\title{
Promotion of Renewable Energy Sources in the European Union
}

\author{
Roland Mengesa and Wolfgang Pfaffenberger ${ }^{*}$ \\ a Technische Universität Clausthal, GERMANY \\ ${ }^{b}$ Jacobs University Bremen, GERMANY
}

\begin{abstract}
One of the important goals of European energy policy is to increase the share of renewable energy resources in the energy supply. The instruments used in the member states are not fully compatible with the rules of the European internal market. In a theoretical section, this paper analyses possible different instruments for promoting renewable energy. Some countries use feed in tariffs - using fixed prices to increase incentives for producers to invest into renewable energy, other countries use quantity-based systems like quotas that lead to a premium above the market price. In an institutional analysis we show that on the basis of effectiveness and efficiency considerations for the European Union, in the long-term quantity oriented systems of promotion are preferable if combined with elements of a capacity market. The main reason for this conclusion is that price-based systems cannot give enough incentives for backup capacities necessary to cope with intermittent production of renewable sources. In addition price-based systems violate the basic rules of the open internal European market because feed in tariffs are a considerable barrier for trade of renewable energy products.
\end{abstract}

Keywords: Promotion of RES, Policy, European Union

Article History: Received March 15, 2015; Received in revised form July 10, 2015; Accepted October 10, 2015; Available online How to Cite This Article: Menges, R. \& Pfaffenberger, W. (2015) Promotion of Renewable Energy Sources in the European Union. Int. Journal of Renewable Energy Development, 4(3),171-180. http://dx.doi.org/10.14710/ijred.4.3.171-180

\section{Introduction : Market failure and market intervention in the field of renewable energy}

In European countries renewable energy policy is evolving rapidly. The reasons for this are the structural changes in the energy and environment policy framework and the role renewable energy can perform in reducing greenhouse gas emissions effectively. In addition to price regulation mechanisms and capital subsidies, some market based policies such as competitive bidding procedures, quota models with certificate trading or renewable portfolio standards have become more common during recent years. Quantity based policies control the quantity of electricity, whereas price mechanisms control the price of green electricity. These policy measures are legitimated by market failure, because environmental quality constitutes a public good and because the use of conventional fossil fuels gives rise to negative externalities, especially greenhouse gas emissions. In

\footnotetext{
* Corresponding author: Tel. 0049441219 3882, Fax: 00494419570962 Email: pfaffen@ewetel.net
}

this way governments explicitly take responsibility to ensure an adequate standard of environmental quality.

Although there has been progress in several renewable energy technologies, most of them have not reached an adequate level of economic performance as compared to "traditional" energy technologies. Hence, they cannot compete directly with these technologies. From an economic perspective, the most efficient solution for establishing a fair level of competition between different technologies in the field of climate policy is the implementation of an optimal environmental tax or an international system of controlling and trading $\mathrm{CO}_{2}$-allowances without any distinction between different technologies. The introduction of taxes or $\mathrm{CO}_{2}$-allowances to correct for externalities is in line with the well-known polluterpays principle because incentives for both, producers and consumers, are created to avoid emissions without pre-scribing certain technologies or measures.

For instance, they could switch to renewable energy sources (RES) or invest in efficiency projects to 
Citation: Menges, R. \& Pfaffenberger, W. (2015) Promotion of Renewable Energy Sources in the European Union. Int. Journal of Renewable Energy Development, 4(3),171-180, http://dx.doi.org/10.14710/ijred.4.3.171-180

$\mathrm{P}$ a g e 172

avoid greenhouse gases. However in reality $\mathrm{CO}_{2}$-related taxes or the system of trading $\mathrm{CO}_{2}$-allowances face many problems in terms of political and technical feasibility. Moreover, many commentators fear that broadly oriented instruments such as emissions trading or $\mathrm{CO}_{2}$-taxes are not sufficient to stimulate the needed dynamic learning process in order to bring costs down (Menanteau et al. 2003). On one hand, creating direct incentives for producers to invest in renewable energy by paying subsidies might increase the systems effectiveness in terms of technological change. On the other hand, cost efficiency of climate policy in general might be worsened by an interplay of different instruments which are directed to the same goal.

As compared to the polluter-pays-principle, which is applied when energy or $\mathrm{CO}_{2}$ is taxed directly, paying subsidies to renewable energy producers is in perfect accordance with the public-pays principle. The possibility to choose between alternative approaches to support green electricity gives rise to a number of normative questions. Apart from the fundamental judgment of which policy measures are to be taken in order to transform collective environmental objectives into individual behaviour, one has to decide how the costs of improving environmental quality are to be shared. In addition to their effects on the allocation of resources, principles such as the polluter-pays or public-pays principles describe different cost-sharing methodologies (Menges \& Traub 2009).

\section{Criteria for evaluating of different policies}

As pointed out above, the major argument to support renewable energy directly or indirectly is based on the market failure hypothesis (i.e. the market mechanism does not account for the full range of aspects which are beneficial for society). Society benefits from renewable energy in terms of environmental quality and its contribution to security of supply. Criteria such as economic efficiency and environmental effectiveness can be used to evaluate different policies.

\subsection{Environmental aspects}

Generating electricity with RES means substituting conventional energy sources and thereby saving scarce fossil resources and reducing greenhouse gas emissions. As economic theory treats the prevention of negative externalities and the provision of public goods as two sides of the same coin, the generation of electricity with RES contributes to a public good. However, this direct link between renewable energy and negative externalities is based on the unrealistic assumption that there is no other mechanism available to internalize external effects: renewable energy is supposed to become the exclusive instrument to internalize external effects and mitigate climate change. In reality, Germany as well as the European Union have implemented a set of different sector specific instruments in order to reduce greenhouse gas emissions. Some commentators state that the joint effect of these instruments and the European emissions trading system is significant overregulation and that the support systems for renewable energy as well as other additional environmental policy instruments such as the electricity tax do not have any positive effect on climate protection (Weimann 2008; Häder 2010).

\subsection{Security of supply and import dependence}

As energy security issues are prominent for countries and regions which depend heavily on imported fossil fuels like natural gas and oil, supporting renewable electricity might help to overcome this kind of import dependence and avoid negative shocks and distortions form the world market for gas and oil (Schmalensee 2012). Moreover, facing the exhaustibility of fossil fuels, the ability of world markets to transform scarcity into prices might be limited. RES tends to establish a so-called backstop technology which forms a long-term insurance against import and resource dependence. As the competitive market does not reward investments in this technology at current prices, society might benefit from paying a premium to green electricity producers. This is because they establish a technological basis, which can be exploited in the future. This contribution to long-term supply security is treated as sustainability effect of renewable energy: because current generations benefit from consuming exhaustible resources, inter-temporal welfare maximization postulates that they should invest evolving scarcity rents from increasing market prices of resources in the development of backstop technologies. This in turn allows future generations to achieve at least a sustained level of welfare (Hartwick-Rule, Perman et al. 2012).

However, there is no linear positive effect of renewable energy on supply security, because the output from most renewable energy power plants such as wind and solar is variable and imperfectly predictable. The increasing share of variable resources tends to challenge the inherent system stability of the electricity system and might increase the need for reserve capacities. The composite effect of renewable energy on security of supply cannot easily be quantified because it depends on the market structure and the regulation of the whole energy system. Moreover, supply-side security effects imply technical, political and cultural issues.

\subsection{Efficiency of supporting RES}

Economic aspects primarily belong to the notion of efficiency, which relates the cost of a certain measure to its objective. Economic efficiency of a certain renewable energy investment asks whether the project objectives 
are achieved in a cost effective manner. In order to evaluate a certain renewable energy policy economic efficiency introduces a more comparative perspective and treats efficiency as Pareto optimality. Therefore, efficiency seeks to identify the optimum allocation at which it is impossible to reallocate resources to make one person in the economy better off without making someone else worse off. Basically, given certain assumptions well defined markets should lead to an efficient allocation of resources in this sense. Economic theory states that short-term static (cost-) efficiency of environmental policy is achieved, when all projects within the system deliver their services for the same level of marginal abatement cost. The short-term refers to a period when capital goods are assumed to be fixed. In renewable energy policy static efficiency includes the efficiency of running existing generating capacity and the way the costs and benefits of operating these plants is allocated to society.

As long as, for instance, certain power plants deliver their service (in terms of $\mathrm{CO}_{2}$-avoidance) for different marginal costs, the whole of society could benefit from reducing the opportunity cost of a given environmental policy goal by reallocating the services from the high-cost to the low-cost plant. Moreover, economic efficiency also includes long-term dynamic aspects, when the use of capital becomes variable. The degree of dynamic efficiency reflects how in the longterm the proper economic incentives are created to stimulate investment in capital goods, thus giving rise to technology improvements and cost reductions. In renewable energy policy dynamic efficiency refers to the efficiency of investment and exploitation of generating capacity, the effects on technological development, and the way the costs and benefits of investment and technology developments are allocated to society in the long run (Van Djik et al. 2003).

\subsection{Effectiveness}

A more pragmatic way to analyze the performance of a mechanism to support renewable energy is to measure its effectiveness in terms of market shares of investments in installed capacities or by generation measures. This because "the core objective of a promotion scheme for RES must be to increase its market deployment" (Haas et al. p 2188). Although any kind of political instrument to support renewable energy belongs to market intervention and includes certain elements of planned economy, one may state that it will be private or public companies who have to decide whether to invest on free markets or not. Basically, in all cases of renewable energy programs, market shares of RES will increase as proper incentives are provided by the system. Hence, the effectiveness of the program relies on artificial markets and depends on the structure and quality of its artificial demand (Haas et al. 2011).

\subsection{Acceptance}

Most systems to support RES create an artificial market and cause a financial burden to the public which is shared by electricity customers or tax payers. Hence, another major criterion for a successful promotion system is acceptance by electricity customers and by society because the payment mechanism affects the distribution of income. This in turn increases the political demand for reimbursement clauses for certain groups of consumers such as low-income households or energy intensive industries. Acceptance strongly depends on the magnitude of overall support. The empirical literature shows that there is a high level of acceptance of renewable energy policies by energy consumers (Menges \& Traub 2009). The results of these studies suggest that the potential of market-endogenous voluntary demand for renewable energy seems to be rather limited due to the large extent of free-riding. Free-riding represents an important feature of strategic behaviour: individuals expect to benefit from society's contributions to climate protection even if they are not willing to pay for this. Voluntary individual contributions become less attractive when individuals fear that others can ride free. Experimental evidence indicates that people interpret the promotion of green electricity - the provision and improvement of environmental quality - mainly as a public duty. Individuals seem to prefer binding collective contributions rather than individual market-driven activities in this field (Quite interestingly, studies of USAmerican consumer preferences deliver opposing results. Wiser shows that private provision of renewable energy elicits a somewhat higher WTP than does government provision (Wiser 2007). This interpretation is compatible with the more general political economy argument in environmental policy that voters (and also politicians) prefer an improvement of the environment by means of regulations and prohibitions over market-driven activities. Direct regulation leads to less visible costs but promises immediate results, whereas market-oriented instruments need time to make an impact because market participants have to adapt their strategies (Schneider \& Volkerts 1999). However, as financial burdens increase with market shares of renewable energy, society's acceptance of renewable energy policy faces another kind of trade-off: the goals of ecological and social sustainability conflict with each other where renewable energy policy measures make energy consumption more expensive and give rise to significant regressive distributional effects as low-income households tend to be more affected by increasing energy prices than high-income households. 
Citation: Menges, R. \& Pfaffenberger, W. (2015) Promotion of Renewable Energy Sources in the European Union. Int. Journal of Renewable Energy Development, 4(3),171-180, http://dx.doi.org/10.14710/ijred.4.3.171-180

P a g e $\mid \mathbf{1 7 4}$

\section{Instruments for the promotion of RES}

\subsection{Renewable energy policy in different sectors of the economy}

According to the strategy of EU policy, renewable energy sources should achieve a certain level of market share in the electricity, heat market and transport markets. In this paper we concentrate on the electricity market, because consumers and producers are connected by the grid, which forms a natural monopoly. This monopoly excludes any kind of substitution possibility on the demand side and enables policy to control consumer and producer decisions directly. If policy, for instance, obliges household consumers to pay a fee for renewable energy, this fee affects consumer decisions in the same way as a consumption tax. However the energy system does not allow for switching to untaxed alternatives. In summary, the natural monopoly creates a transparent border separating demand and production activities as well as constitutes a practical framework for an effective regulation of prices, quantities and even qualities. In other sectors such as the heat market or the transport sector a prominent and increasing role of renewable energy might also be desired. However, a similar leverage for effective regulation is not available because of various substitution possibilities within and between both sides of the market.

\subsection{Quantity versus price-based models}

Basically speaking, any market can be described as an interaction of (supplied and demanded) quantities with prices. Political interventions belong to attempts of controlling either prices or quantities. Hence, within the category of regulatory instruments to support renewable energy one has to distinguish between pricedriven and quantity-driven strategies (Menanteau et al. 2003; Van Dijk et al. 2003; Haas et al. 2011).

- Price-driven strategies such as feed in tariffs focus on providing generators of electricity with financial support in terms of a subsidy per kW of capacity installed or a payment per kWh of energy produced. There are a number of variations under this scheme such as investment focused strategies (where financial support is provided through investment subsidies per unit of generating capacity installed) or generation based strategies (where financial support is paid as a fixed payment or as a premium per unit of energy generated). In most cases generators receive a fixed amount per $\mathrm{kWh}$ generated regardless of the costs of generation or price. However, more flexible systems, such as in Spain, only pay a premium and introduce more volatile price elements (where a fixed amount is added to the electricity price obtained from the competitive wholesale market) (Haas et al. 2011). As the supply price is fixed by regulatory authorities, the resulting quantity becomes more or less endogenous and therefore cannot be controlled directly. However, in order to control the technology mix policy is able to set different prices for different renewable energy technologies.

- In contrast quantity-driven strategies are based on a government decision on the desired level of generation or market penetration of renewable energy. Such a system aims to support new renewable energy generation by setting and increasing an artificial demand for renewable electricity by defining a certain proportion of electricity supply that must be produced from renewable energy sources. The quantity obligation is typically imposed on consumption, often through supply or distribution companies, but it might also be applied to electricity producers. The enforcement of a quota system must involve a penalty for non-compliance. Opposed to pricesetting policies the price within a quota system becomes endogenous and is therefore set through competition between different generators of renewable energy. Applications of quantityoriented regulation include tendering schemes (which call for tenders to acquire specific amounts of capacity or generation from pre-specified renewable energy technologies) and tradable certificate schemes. Basically, as green electricity tends to substitute conventional non-renewable energy sources, green electricity certificates belong to a separation of the physical output of a generator (measured in terms of kWh electricity) and its environmental benefit (in terms of $\mathrm{MWh}$ of conventional generation avoided, thus leading to certain savings of scarce resources and greenhouse gas emissions). A system of tradable green certificates typically involves actors of the electricity supply chain, such as wholesalers, distribution and retail companies, acquiring a certain percentage of electricity from RES in terms of green certificates. Green certificates allow for some degree of freedom of market participants: certificates can be obtained by their own renewable electricity generation, by purchasing renewable electricity and associated certificates from other generators, or by buying only certificates on the market. The price of the certificates is determined by the market, thus allowing for a certain level of competition within the protected market segment.

In addition to these main regulatory strategies to stimulate renewable energy, some other measures such as financial subsidies (e.g. for research and development or certain investments in technologies) or tax incentives (such as tax exemptions for producers and/or consumers of renewable energy) can be used. Moreover, green marketing campaigns where consumers pay mark-ups for certain green electricity 
products, are sometimes also included in the set of political instruments used to support renewable energy.

During recent years the discussion focused more on the interaction between renewable energy and the electricity system. Bauknecht et al., identify two dimensions of interaction between a growing share of renewable energy sources and the current competitive electricity market. Interestingly, the question of whether quota models or a feed-in-mechanism are used for supporting renewable energy is not of primary interest here. On one hand growing shares of RES affect the short-term balance between demand and supply as they do not react to market signals in a proper way. On the other hand, the large-scale integration of RES leads to the reduction of variable-cost-oriented wholesale prices (merit order effect) and gives rise to the so-called investment paradox or the "missing money problem" on energy-only markets. Similarly, Bauknecht et al. evaluate the long-term revenues of intermittent energy sources such as wind and photovoltaic using a high resolution power market model for scenarios with different $\mathrm{CO}_{2}$-prices and spot market prices. Assuming that long-term market integration means that renewable energy sources have to cover their full costs from revenues on competitive markets, they conclude that RES cannot be financed through power market prices alone. Moreover, this conclusion is still valid even if the full costs of RES fall below cost levels of conventional power plants. (Kopp et al., 2012). Additionally it highlights the need to implement an additional capacity mechanism complementing the competitive and decentralized market mechanism.

\section{Compatibility with European Market and Policy}

\subsection{Internal market in Europe}

The EU is a federation of 27 nations. To some extent the individual nations maintain independent decisions; to some extent the EU sets the framework for legislation. In the Treaty of Lisbon it was agreed that the EU has a shared competence for energy policy. If the EU decides to regulate certain matters within energy policy, the member states must follow the European rule (EU 2009). In general, however, the EU is essentially characterized by a complete removal of all barriers for trade within the union. Such barriers are quality standards for products, taxes and subsidies.

Harmonization of all current relevant rules is politically difficult. Step-by-step harmonization is the standard. In practice there are many obstacles to the free exchange of goods and services between member countries of the EU resulting from national taxation, subsidies and specific quality standards. There is a permanent tension between the national interest to promote own industries and the European rules of an open market.
What are the implications for the promotion of renewable energies? It is best to explain this with the help of an example. Assume that a Danish wind energy producer adjacent to the border between Denmark and Germany wants to sell his electricity to the German network operator next to the border because the feed in tariff in Germany is higher. In the present situation the Danish producer could not profit from the German feed in conditions. Different rules between the two countries are definitely an obstacle to free exchange of goods and services within the EU.

Using national rules the promotion of RES follows national targets. This leads to two questions:

1. Are national targets and national instruments of promotion compatible with the open European market?

2. Can national instruments of promotion lead to effective and efficient solutions?

\subsection{Compatibility of Promotion with the European market}

The European Internal Market became effective twenty years ago in 1992. Free exchange of commodities and services is the general intention and was created by abolishing price and non-price barriers to trade and exchange. The energy industry was at the time organized on the basis of regional or national monopolies. In several steps the markets for electricity and natural gas were opened on the basis of a number of directives that had to be implemented by the member states. Gradually the main obstacles, listed below, to the open internal market for electricity have been removed:

- Conditions for use of transmission network.

- Creation of open wholesale markets.

- Unbundling of network operation from trade and generation.

Electricity trade plays an important role ensuring that a least cost solution for the use of generation units is found within the limits of the available transmission system and while observing the rules of network stability. In the electricity industry production has to be simultaneous with consumption. This is only possible if adequate reserves are held. Trade can also help to reduce the reserve requirements by allowing access to capacities in other regions. For example, peak load hydro power plants in the alpine region are used for this purpose.

\subsection{Transmission}

The integration of the European power system requires sufficient transmission capacities to serve the functions mentioned. A remarkable increase of intermittent renewable electricity fed into the network 
Citation: Menges, R. \& Pfaffenberger, W. (2015) Promotion of Renewable Energy Sources in the European Union. Int. Journal of Renewable Energy Development, 4(3),171-180, http://dx.doi.org/10.14710/ijred.4.3.171-180

$\mathrm{P}$ a g e $1 \mathbf{1 7 6}$

challenges the existing transmission network in the following way:

- The distance between points of generation and points of consumption increases

- Intermittent generation has to be stabilized by generating units at different locations

Both transport of electricity from more distant sources and the need for reserve power for intermittent sources require additional investment in the transmission system and also have consequences for the operation of the network.

The European commission has estimated the investment needs for network improvement and extension at about 200 billion $€$. For Germany about 20 billion $€$ are required to improve the transmission system and another 20 billion to connect the offshore wind plants to the grid (EU 2010; Netzentwicklungsplan 2012). Networks in the European system are regulated monopolies and thus additional cost caused by the expansion of RES can be charged to the consumers if the regulator has accepted the investment. Thus, the national regulator can indirectly decide on the investment for the transmission system. As the rising share of RES leads to transfer of power between member states, there may be conflicts about the network adaption. There is no European regulator to solve the conflicts, but it is hoped that the cooperation of national regulators will be able to solve the disputes of transmission system operators (TSOs) on the development of the national grids and the trans-border capacity.

At present "there is congestion on internal German transmission lines. Because electrons follow the path of least resistance, wind power has been spilling over in 'loop flows' into Poland and the Czech republic in the east and the Netherlands in the west. These countries have now placed so called phase shifting transformers on their borders with Germany to prevent their grids being disrupted" (Buchan p. 5).

What incentives are there for the TSO to invest into the transmission grid according to the requirements caused by the rising share of intermittent RES? Investment incentives would result from so-called nodal pricing. Network pricing then depends on the load in specific segments of the grid (Knieps 2013). This system is not currently implemented, so at present incentives must result from the political and administrative process in the development of so-called network expansion plans according to European and national regulation. TSOs are monopolists and network pricing is regulated. On one hand the TSO is legally obliged to secure adequate transmission services. On the other hand the regulator can decide the acceptable cost basis for network pricing.

In theory this is a consistent model. However, in practice there may be strong conflicts between the regulator representing the public wish for a stable and reliable network and the financial considerations of a private network operating company that must take care of the interests of the shareholders and the capital market. In the traditional vertically integrated system of generation, transmission and retail, the network operator had a genuine interest to supply the network services required because the network is the bridge between generation and retail. Any failure of the network would lead to reduced sales or production of electricity.

In the present vertically disintegrated or unbundled system, the TSO has no direct economic interest in generation or retail, which in turn reduces his interest in a smooth cooperation of the different parts of the electricity system. Traditionally in the electricity and natural gas business large expansions of the transport network have been developed by producers or retailers and were not independent of the core business. Producers of offshore wind energy, for example are highly dependent on the availability and stability of the transmission system. By law it is the task of an onshore TSO to transport offshore electricity to the onshore grid. This law was passed in order to relieve potential offshore producers from the transport cost. From an economic point of view it would be much better if the producers of offshore wind would also invest into the necessary grid development on a cooperative basis. In the oil industry it is quite common that pipelines are developed and operated by several companies together. If producers are also responsible for the network they have a genuine interest in a reliable and stable operation of the transmission system. If the transmission system fails, this causes internal problems between the producer and the transmission company, but does not require public liability regulation.

Such a model, however, does not fit into the present system of promotion for renewable energy. The renewable product receives a product price set by the feed in tariff, and this price is independent of any transport elements. The order of magnitude for investing into offshore grid connections is enormous and therefore it would be quite adequate to ensure that the checks and balances of an open market can be used to avoid overpricing and over-costing. By unbundling networks from the other segments of the electricity system, the European policy went in a different direction.

European policy sees the need for expanding and improving the transmission grid in Europe, but the implementation has to be done by TSOs. There will need to be a learning process in the interaction of regulators and TSOs in the future.

\subsection{Generation}

The electricity sector was gradually opened for competition by several European directives. A 
wholesale market now exists that works within and between European countries. Spot and future products can be traded on the market and the prices resulting from these transactions have a strong influence on all direct contracts between producers and retailers. Transactions are time sensitive and the market usually is organized on an hourly basis. In a way the electricity wholesale market follows the textbook pattern of market organization.

When the market was opened there was enough production capacity available in the European countries (then the EU 15), and therefore the market operation could concentrate on the allocation of existing generation units to the market demand. There was certain doubt that the market could cope with investment needed for a rising demand or for the replacement of old generation units. The question is whether the average electricity prices over all hours of the year resulting from the interaction of supply and demand in that year are sufficient to support new generation units with their full cost of fuel, O\&M and capex.

This question arises because at times of lower demand the price will be determined on the basis of the marginal cost of the plant necessary to satisfy the quantity demanded. This marginal cost does not contain capex and may not be sufficient to support the investment in a new plant. What is the influence of the promotion of renewable energies on the power market?

If renewable energies for electricity production are promoted outside of the mechanisms of the wholesale market, additional production of renewable electricity reduces the production of conventional electricity and leads to a price reduction in the market for conventional electricity.

Figure 1 shows the merit order of generation units ordered by their marginal cost. If renewable energy adds to production outside of the wholesale market this is equivalent to a reduction in demand for conventional electricity. In the diagram this is shown by the arrow between the dotted vertical line and the thick vertical line to the left of it. Thus the price in a situation with considerable production from renewable energy is reduced because only lower cost units of the conventional portfolio must contribute. This has consequences for investment into conventional generation. The resulting lower prices may not be sufficient to cover the full cost of new generation units. In other words: the market that was created by the various European directives and the promotion of renewable energy outside of the market mechanism are in conflict with each other.

This was definitely not a problem in the early phase of promotion of RES. State intervention to compensate for the cost difference between conventional and renewable generation helped to set up the market for RES. The rising share of RES producing and selling outside of the market mechanism however, questions the market mechanism as whole. Intermittent RES cannot guarantee the necessary stability in the electricity system. An increasing share of intermittent renewable generation units requires corresponding capacities to compensate for the fluctuations. The present market mechanism is not able to generate the necessary incentives to ensure that the variation of electricity demand during days, seasons and the year can be compensated by sufficient conventional capacity. Instead of conventional generation capacity, measures of demand-side management or storage of electricity could also help resolve the stability problem. This is however outside of the topic of this paper.

The European idea of an open market relates to the market rules inside of member states and also to the

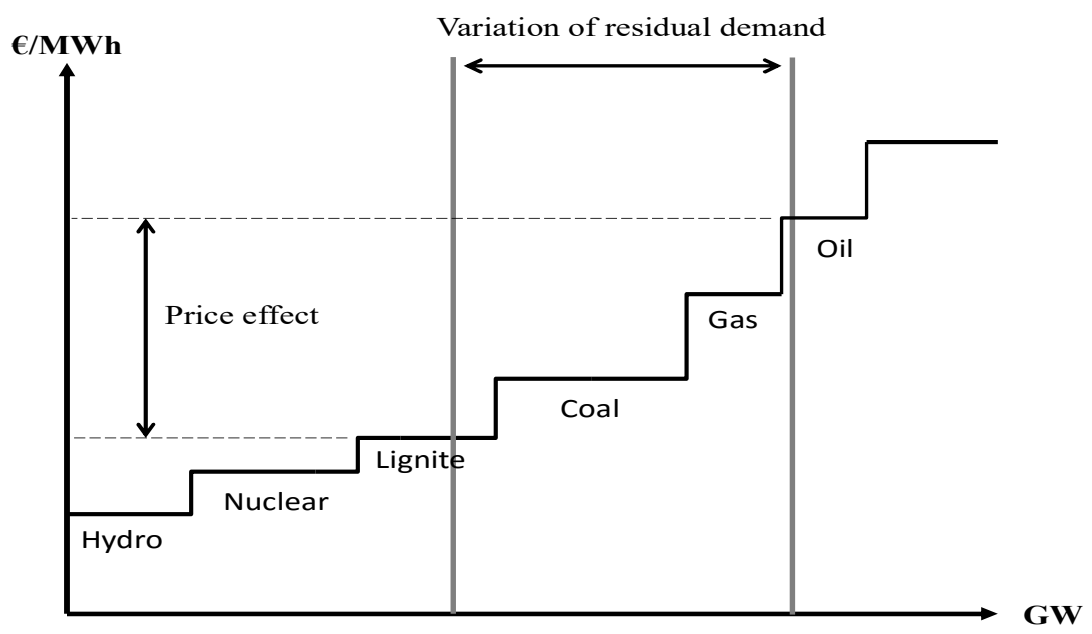

Fig. 1 Merit order with renewable energy 
Citation: Menges, R. \& Pfaffenberger, W. (2015) Promotion of Renewable Energy Sources in the European Union. Int. Journal of Renewable Energy Development, 4(3),171-180, http://dx.doi.org/10.14710/ijred.4.3.171-180

$\mathrm{P}$ a g e $1 \mathbf{1 7 8}$

exchange of electricity between countries. Regarding the exchange between countries, national systems of promotion violate the rules of the European internal market in two ways:

- National systems of promotion exclude import / export relationships on the basis of the same conditions, especially price.

- The basic principle of trade that countries should specialize on the products that have a comparative advantage is also violated. The potential of renewable energy as a natural resource is based on natural factors. There are considerable comparable advantages or disadvantages between countries and regions. In order to use the best combination of renewable energy sources borders should be open.

\subsection{Effectiveness and efficiency}

Promotion of renewable energies is effective, when it is able to create new markets including the whole chain of production from machinery, equipment to operation, management of generating units and the marketing of the products (see also section 3.2).

A system based on a feed in tariff is effective as far as it can reduce the investment risk and guarantee sufficient and reliable income for all parts of the value chain. This is basically a question of the level of the feed in tariff and the time guaranteed to investors for stable prices. Because feed in tariffs also guarantee the sale of the product (feed in priority), the conditions for investment are very comfortable and better than in many other parts of the economy. It therefore can be expected that feed in tariffs, given an appropriate level of prices will be effective.

Effectiveness is an important criterion for policymakers, because it guarantees the success of certain policies. Are effective policies also efficient? Promotion of renewable energies is efficient, when it leads to a mix of renewable energies that guarantees the lowest possible cost for the portfolio of renewable production of electricity. This has two implications:

- Which renewable energy should be chosen to achieve a low cost solution?

- How can we deal with RES that are currently high cost, but may promise long-term benefits if developed?

Both points have a clear inter-European significance: the economic potential for renewable energies is not distributed evenly within the European member states. An efficient strategy should allow for the use of potential RES in other EU countries or countries outside of the EU. If cost efficiency is the main criterion for choice between renewable energies then it is likely that certain options will not be used and therefore not developed, because relative to others, the cost is too high. Potential long-term benefits of such options will not be considered if cost efficiency is the only principle. A cost-efficient system also needs certain corrections to allow for the development of new options. Even then the comparative advantage of certain regions / states must be considered.

\subsection{The proposed reform of 2008}

In 2008 the EU proposed a quantity oriented approach toward the promotion of RES. Qualified producers of renewable energy receive certificates: for consumers an obligation to buy is defined. Producers receive the wholesale price for electricity plus the revenue from selling the certificates. Because of the obligation to buy the demand for certificates arises automatically. Consumers or retailers have to prove an amount of certificates corresponding to the required share of renewables in their portfolio (EU 2009).

This proposed system has advantages and disadvantages: the main advantage is the introduction of a competitive element between nations which would lead to an effective production of renewable energy in the locations with best natural conditions. The system is in line with the rules of the internal European market.

There are, however several disadvantages:

1. The system prefers low-cost renewable energies. Due to the strong cost differences between different renewable energies for electricity production, high cost alternatives will only be developed when the potential of low-cost options is exploited. When high cost options contribute to production they will also set the price in these periods, which will lead to high windfall profits for the low-cost producers.

2. Prices for certificates may be variable and even volatile so that the investment incentives may be reduced and the development of the market may be retarded.

The system was not adopted; one of the main reasons being that member countries preferred to subsidize their own renewable production rather than transferring money to other member states. According to the present rules certain elements of trade between member countries to fulfil their renewable targets are possible (see next section).

\subsection{Present Policy}

The present European target is to reach a level of $20 \%$ of final energy consumption covered by RES in the year 2020. For the transport sector the target at the moment is $10 \%$, but may be reduced in the future. This implies that the other relevant sectors (heat and electricity) must reach considerably more than $20 \%$. For the member countries individual targets have been 
defined considering their potential, their economic development and the share they have already reached in the past. It is quite clear that the European target of a share of $20 \%$ is of an indicative nature. There is no way to guarantee that the efforts in different countries will average at the European target level of $20 \%$.

In order to make sure that member countries develop renewable energy to reach the indicative target, the EU has chosen a bureaucratic approach. Member countries have to report continuously on the level reached. For each country in addition to the target for 2020 a path leading to this target has been defined so that deviation from the target path can be controlled. Whether and how far this is politically viable can be doubted.

A certain market element is included. If certain conditions are met (particularly regarding the availability of transport capacity) countries can partly fulfil the national target by using renewable energy from other countries even outside of the EU (e.g. Switzerland, Norway).

\section{Conclusion}

There is a strong contradiction between the open European market and national targets for the development of renewable energy. As we have shown there is a strong tension between efficiency and effectiveness. The theoretical considerations in the first part of this paper and the analysis of the institutional framework of policy in Europe suggest the following conclusions.

Elements of competition need to be introduced so that efficiency in using potential renewable energy sources is increased. Feed in tariffs at present lead to strategic games between producers and government and overproduction or overinvestment, depending on politically regulated prices. At the same time the conventional market becomes the scapegoat of renewable energy promotion which leads to long-term stability problems in the system.

Because marginal cost for many renewable energy options, (biomass being the exception) is almost zero, a market oriented approach will never lead to sufficient investment incentives to guarantee expansion of renewable energy and its contribution to electricity production. Therefore elements of a capacity market combined with renewable energy obligation should be the answer. This would also automatically help to secure enough reserve capacity required for system stability. In a capacity market enough investment is secured by paying capacity payments in addition to the payments for the produced energy units. (Crampton et al.2012): An important point in that respect is the scope of such a capacity market. To consequently implement the European internal market and its efficiency potential, the scope of the capacity market should be European or at least be based on combinations of adjacent member states to form capacity regions. Studies show that the cost of stabilizing the system on a national basis leads to considerably higher overall cost (Maurer et al.2012).

In the long-term promotion of renewable energy should also consider the technology mix. To promote certain technologies that are not yet competitive, all the classical instruments available should be used (R\&D grants, tax incentives etc.). Feed in tariffs could also be used as long as the quantity to be promoted is politically defined and limited.

\section{References}

Bauknecht, D., Brunekreeft, G. and Meyer, R. (2013). The Evolution of Renewable Energy in the German Electricity Market. Evolution of Global Electricity Markets (ed. P. Sioshansi). Elsevier, Amsterdam, 169-198

Buchan, D. (2012) The Energiewende - Germany's gamble. Oxford: The Oxford Institute for Energy Studies.

Cramton, P. and Ockenfels, A. (2012) Economics and Deisgn of Capacity markets for the Power Sector. Zeitschrift für Energiewirtschaft. 36, 113-134.

EU (2009) Treaty on the functioning of the European Union, Brussels.

EU. Energy 2020, A strategy for competitive, sustainable and secure energy, COM(2010) 639 final. Brüssel.

EU. Richtlinie zur Förderung der Nutzung von Energie aus erneuerbaren Quellen, 2009/28/EG. Brüssel.

Haas, R, Eichhammer, W, Huber, C, Langniss, O, Lorenzoni, A, Madlener, R, Menanteau, P, Morthorst, PE, Martins, A, Oniszk, A, Schleich, J, Smith, A, Vass, Z \& Verbrüggen, A. (2004) How to Promote Renewable Energy Systems Successfully and Effectively. Energy Policy. 2004, 32, 833-839.

Haas, R., Resch, G., Panzer, C., Busch, S., Ragwitz, M., and Held, A. (2011) Efficiency and effectiveness of promotion systems for electricity generation from renewable energy sources Lessons from EU countries. Energy, 36, 2186-2193.

Häder, M. (2010) Klimaschutzpolitik in Deutschland - eine ökonomische Konsistenzanalyse der Rahmenbedingungen für den Strommarkt, Zeitschrift für Energiewirtschaft, 11-19.

Knieps, G. (2013) Renewable energy, efficient electricity networks and sector-specific market regulation. Evolution of Global Electricity Markets (ed. P. Sioshansi). Elsevier, Amsterdam, 147-168

Kopp, O., Eßer-Frey, A. and Engelhorn, T. (2012) Können sich erneuerbare Energien langfristig auf wettbewerblich organsierten Strommärkten finanzieren? Zeitschrift für Energiewirtschaft., 36, 243-255

Maurer, C., Tersteegen, B. and Zimmer, C. (2012) Anforderungen an den konventionellen Kraftwerkspark - wieviel und welche Kraftwerkskapazität wird benötigt. Zeitschrift für Energiewirtschaft, 36, 147-154.

Menanteau, P., Finon, D. and Lamy, M.-L. (2003) Prices versus Quantities - Choosing Policies for Promoting the Development of Renewable Energy. Energy Policy, 31, 799-812.

Menges, R. and Traub, S. (2009) An Experimental Study on the Gap between Willingness to Pay and Willingness to Donate for Green Electricity. Finanzarchiv, 335-357.

Netzentwicklungsplan (2012). Netzentwicklungsplan Strom 2012 Entwurf der Übertragungsnetzbetreiber, Berlin www.netzentwicklungsplan.de.

Perman, R., Ma,Y., McGilvray, J. and Common, M. (2012) Natural Resource and Environmental Economics. 4th ed. Essex .

Schmalensee, R. (2012) Evaluating Policies to Increase Electricity Generation from Renewable Energy. Review of Environmental Economics and Policy. 45-64. 
Citation: Menges, R. \& Pfaffenberger, W. (2015) Promotion of Renewable Energy Sources in the European Union. Int. Journal of Renewable Energy Development, 4(3),171-180, http://dx.doi.org/10.14710/ijred.4.3.171-180

P a g e $\mid \mathbf{1 8 0}$

Schneider, F. and Volkerts, J. (1999) No Chance for Incentive-oriented Environmental Policies in Representative Democracies? A Public Choice Analysis. Ecological Economics, 123-138.

Van Dijk, A. (2003) Renewable Energy Policies and Market Developments. Amsterdam : ECN Project report number 7.4114

Weimann, J. (2008) Die Klimapolitikkatastrophe. Marburg : Metropolis.
Weitzman, M.L. (1974) Prices vs. Quantities. The Review of Economic Studies. 41, 477-491.

Wiser, R. (2007) Using Contingent Valuation to Explore Willingness to Pay for Renewable Energy: A Comparison of Collective and Voluntary Payment Vehicles. Ecological Economics, 419-432. 